\title{
PERBEDAAN PENGETAHUAN IBU BALITA SEBELUM DAN SESUDAH DIBERI PENYULUHAN TUMBUH KEMBANG BALITA
}

\author{
Eliya Rohmah ${ }^{1}$, Murniati ${ }^{2}$, Endang Safitri ${ }^{3}$ \\ 1,2,3 Akbid Harapan Mulya Ponorogo \\ Email : eliyarohmah8@gmail.com
}

\begin{abstract}
Abstrak
Pertumbuhan adalah peningkatan ukuran organ tubuh. Pengembangan adalah peningkatan kemampuan atau keterampilan struktur dan fungsi yang kompleks dan teratur. Berdasarkan data di Posyandu Dukuh Nogo, Desa Karang Waluh, Kecamatan Sampung, Kabupaten Ponorogo, terdapat 43 anak di bawah lima tahun, 1 balita yang mengalami gangguan pertumbuhan, yang menyebabkan 1 balita menderita autisme dan 1 balita mengalami gangguan bahasa. Penelitian ini bertujuan untuk mengetahui perbedaan pengetahuan ibu balita sebelum dan sesudah diberikan penyuluhan tentang pertumbuhan balita di Posyandu Dukuh Nogo Karang. Desa Waluh, Kecamatan Sampung, Kabupaten Ponorogo. Jenis penelitian ini adalah penelitian Pre Post Test Disign. Metode yang digunakan survei analitik. Alat ukur menggunakan kuesioner. Populasi dan sampel sejumlah 43 ibu dengan teknik total sampling pada bulan April. Untuk analisis data menggunakan paired T-Test dengan tingkat signifikansi 0,05. Hasil penelitian ini menunjukkan bahwa sebelum diberikan konseling ada 26 responden $(60,5 \%)$ berpengetahuan kurang, setelah diberikan konseling ada 24 responden $(55,8 \%)$ berpengetahuan baik. Berdasarkan hasil paired TTest diperoleh nilai $0,000<0,005$ sehingga $\mathrm{H} 0$ ditolak, artinya ada perbedaan pengetahuan ibu sebelum dan sesudah diberikan penyuluhan tentang pertumbuhan balita. Disarankan kepada petugas kesehatan untuk meningkatkan penyuluhan a tentang pertumbuhan balita.
\end{abstract}

Kata kunci: Pengetahuan, Ibu Balita, Konseling, Pertumbuhan dan Perkembangan

\begin{abstract}
Growth is an increase in the size of the body's organs. Development is an increase in the ability or skills of structures and functions that are complex and orderly. Based on data in Posyandu Dukuh Nogo, Karang Waluh Village, Sampung District, Ponorogo Regency, there are 43 children under five years old, 1 toddler who has a growth disorder, which causes 1 toddler suffering from autism and 1 toddler experiencing language disorders. This study aims to determine the differences in the knowledge of mothers under five before and after counseling about the growth of toddlers in Posyandu Dukuh Nogo Karang. Waluh Village, Sampung District, Ponorogo Regency. This type of research is the Pre Post Disign Test. The method used analytic survey. Measuring instruments using a questionnaire. Population and sample were 43 mothers with total sampling technique in April 2018. For data analysis using paired T-Test with a significance level of 0.05 . The results of this study indicate that before being given counseling there were 26 respondents $(60.5 \%)$ lacking knowledge, after being given counseling there were 24 respondents $(55.8 \%)$ well-informed. Based on the results of paired T-Test values obtained 0,000 $<0.005$ so that $\mathrm{H} 0$ is rejected, meaning that there are differences in knowledge of the mother before and after counseling about the growth of infants. It is recommended to health workers to increase counseling about the growth of children under five.
\end{abstract}

Keywords: Knowledge, Mother Toddler, Counseling, Growth and Development 


\section{PENDAHULUAN}

Pembangunan Nasional jangka panjang menitikberatkan pada kualitas sumber daya manusia (SDM) yang tangguh dan produktif. Tujuan tersebut dapat tercapai dengan upaya mengusahakan tumbuh kembang anak seoptimal mungkin setaraf potensinya. Setiap tahapan perkembangan anak merupakan masa yang sangat penting. Namun, setiap anak memilki tahapan perkembangan yang berbeda-beda. Oleh karena itu, ketelitian dari orang tua sangat diperlukan untuk mendorong anak supaya mencapai puncak pekembangan yang optimal (gain moment) (Fida dan Maya, 2012). Istilah tumbuh kembang sebenarnya mencakup dua peristiwa yang sifatnya berbeda, tetapi saling berkaitan dan sulit dipisahkan, yaitu pertumbuhan dan perkembangan. Pertumbuhan (growth) adalah bertambahnya ukuran berbagai organ yang bisa diukur dengan ukuran berat (gram, kilogram) atau ukuran panjang (sentimeter, meter). Perkembangan adalah bertambahnya kemampuan atau keahlian dalam struktur dan fungsi yang kompleks dan dalam pola yang teratur sebagai hasil dari pematangan (Nana Aditya., S. Si, 2014).

Berdasarkan data di Posyandu dukuh Nogo Desa Karang Waluh Kecamatan Sampung Kabupaten Ponorogo, didapatkan jumlah 43 balita, dari jumlah tersebut didapatkan 41 balita yang memiliki pertumbuhan normal sesuai dengan grafik Kartu Menuju Sehat (KMS), sedangkan didapatkan 2 balita yang memiliki gangguan dalam tumbuh kembangnya, yang disebabkan 1 balita tersebut memiliki keterbelakangan mental (autis) dan 1 balita memiliki gangguan bahasa dan dari data SKDN didapatkan S (Jumlah balita yang ada) $=43$, K (Jumlah balita yang terdaftar dan punya KMS $)=43, \mathrm{D}($ Jumlah balita yang ditimbang $)=89,23 \%, \mathrm{~N}$ (Jumlah balita yang naik BB nya $)=79,31 \%$, T (Jumlah balita yang turun/tetap BB nya $)=13,79$ $\%$, O (Jumlah balita yang bulan lalu tidak datang ditimbang di posyandu $)=13,79 \%$. Sedangkan berdasarkan hasil wawancara pendahuluan dari 10 orang ibu balita pada saat kegiatan posyandu pada Bulan Oktober 2017 didapatkan 4 ibu balita (26,66\%) yang mengatakanpernah mendapatkan informasi dari petugas kesehatan yang ada atau bidan tentang tumbuh kembang balita dan agar membawa anaknya keposyandu untuk memantau tumbuh kembang secara optimal. Adapun 6 ibu balita (73,33\%) didapatkan tidak pernah mendapatkan informasi tentang tumbuh kembang balita meskipun datang saat kunjungan posyandu. Dari hasil wawancara tentang pengetahuan ibu balita tentang tumbuh kembang didapatkan dari 10 responden, diperoleh6 orang tidak mengetahui apa yang dimaksud tumbuh kembang, pengertian, maupun penilaian tumbuh kembang dengan alasan tidak pernah mendapatkan informasi atau penyuluhan 
sebelumnya.

Dampak dari gangguan tumbuh kembang pada anak yaitu adanya berkembang yang kurang dibandingkan anak yang mendapat pemantaun tumbuh kembang baik pada motorik kasar, motorik halus, sosialisasi dan kemandirian dan bahasa. Selain itu potensi kecerdasan anak tidak akan berkembang optimal. Sedangkan anak bisa cerdas jika dicukupi kebutuhan untuk pengembangan kecerdasan sejak di dalam kandungan sampai usia sekolah dan remaja. Orangtua yang cerdas, anaknya cenderung akan cerdas pula jika faktor lingkungan mendukung pengembangan kecerdasannya sejak didalam kandungan, masa bayi dan balita. Peran seorang ibu dalam pengasuhan anak, juga dalam memperhatikan tumbuh kembang pada anaknya sangat besar. Karena itu diperlukan pemahaman yang benar mengenai masalah tersebut

Beberapa faktor yang dapat mempengaruhi tumbuh kembang antara lain: faktor herediter, faktor lingkungan, status sosial dan ekonomi keluarga, iklim dan cuaca, olahraga/latihan fisik, posisi anak dalam keluarga, status kesehatan, faktor hormonal. Tumbuh kembang merupakan dua peristiwa yang sifatnya berbeda, tetapi saling berkaitan dan sulit dipisahkan, yaitu pertumbuhan dan perkembangan. Aspek tumbuh kembang pada masa anak merupakan suatu hal yang sangat penting, yang sering diabaikan oleh tenaga kesehatan khususnya di lapangan. Salah satu upaya pemantauan pertumbuhan dan perkembangan balita adalah Stimulasi Deteksi Dini Tumbuh Kembang (SDIDTK). Namun dalam hal ini orangtua juga memerlukan pengetahuan yang cukup dan baik agar dapat mengamati setiap tumbah kembang anak. Karena dari pengetahuan orangtua terutama ibu sebagai pendidik pertama bagi anak sangat menentukan pertumbuhan dan perkembangan anak.

Adanya dampak dari kurangnya pengetahuan ibu balita tentang tumbuh kembang pada anaknya sangat disayangkan karena jika anak mengalami gangguan pertumbuhan maupun perkembangan yang lambat disadari oleh orang tua, dapat berdampak pada pertumbuhan maupun perkembangan anak secara berkelanjutan seperti down shindrom, gangguan bahasa, gangguan kecerdasan. Namun hal itu dapat dicegah dengan cara memberikan penyuluhan pengetahuan pada ibu balita. Dengan adanya pengetahuan ibu yang baik tentang tumbuh kembang pada anaknya dinilai sangat penting, maka ibu memerlukan penyuluhan yang diharapkan mampu meningkatkan pemahaman ibu balita mengenai tumbuh kembang pada anaknya. Pada dasarnya usia balita merupakan masa keemasan (Golden Period),dimana pada masa ini pola asuh dan pendampingan orang tua sangat menentukan dalam hal perkembangan dan pertumbuhan pada anak. 
Periode penting dalam tumbuh kembang anak ini perlu diperhatikan dengan baik oleh ibu, karena pada masa ini pertumbuhan dasar yang akan mempengaruhi danmenentukan perkembangan anak selanjutnya. Oleh karena itu, pada periodekritis ini memerlukan peran orang tua dimana khususnya ibu dalam memperhatikan tumbuh kembang balita yang berguna agar potensianak berkembang secara optimal dan sesuai umurnya. Agar anak dapat bertumbuh kembang secara optimal diperlukan situasi yang mendukung. Keluarga atau orangtua khususnya ibu, merupakan lingkungan yang pertama dan utama bagi seorang anak usia balita. Tahun-tahun pertama kehidupan merupakan periode yang sangat penting karena pertumbuhan fisik, perkembangan kecerdasan, ketrampilan motorik dan sosial emosi berjalan demikian pesatnya.

Berdasarkan latar belakang masalah di atas maka penulis tertarik untuk melakukan penelitian dengan judul "Perbedaan Pengetahuan Ibu Balita sebelum dan sesudah diberi penyuluhan tentang tumbuh kembang balita di Posyandu Dukuh Nogo Desa Karang Waluh Kecamatan Sampung Kabupaten Ponorogo. ”

\section{METODE PENELITIAN}

Penelitian ini menggunakan studi analitik observasional dengan pendekatan cross sectional, yang betujuan untukmenganalisis Perbedaan Pengetahuan Ibu Balita Sebelum dan Sesudah diberi Penyuluhan tentang Tumbuh Kembang Balita di Posyandu Dukuh Nogo Desa Karang Waluh Kecamatan Sampung Kabupaten Ponorogo.Tempat penelitian ini dilakukan di Posyandu Dukuh Nogo Desa Karang Waluh Kecamatan Sampung Kabupaten Ponorogo, sedangkan pada waktu penelitian dilakukan padabulan April 2018. Populasinya dalam penelitian ini adalah Ibu Balita di Posyandu Dukuh Nogo Desa Karang Waluh Kecamatan Sampung Kabupaten Ponorogo, yang berjumlah 42 ibu balita, pada bulan April 2018.Sampel penelitian terdiri dari semua Ibu Balita yang datang di Posyandu Dukuh Nogo Desa Karang Waluh Kecamatan Sampung Kabupaten Ponorogo, pada bulan April 2018, yang sesuai dengan kriteria inklusi.Teknik Sampling pada penelitian ini menggunakan accidental sampling Uji analisis Menggunakan $t$-test. 


\section{HASIL DAN PEMBAHASAN}

Tabel 1 Distribusi Pengetahuan Ibu Balita Sebelum Diberi Penyuluhan Tentang Tumbuh Kembang Balita Di Posyandu Dukuh Nogo Desa Karang Waluh Kecamatan Sampung Kabupaten Ponorogo

\begin{tabular}{cccc}
\hline No. & Pengetahuan & N & $\%$ \\
\hline 1 & Baik & 5 & 11,6 \\
\hline 2 & Cukup & 12 & 27,9 \\
\hline 3 & Kurang & 26 & 60,5 \\
\hline & Total & 43 & 100 \\
\hline
\end{tabular}

Berdasarkan tabel diatas menunjukkan bahwa pengetahuan sebelum diberikan penyuluhan Sebagian besar $26(60,5 \%)$ berpengetahuan kurang.

Tabel 2 Distribusi Pengetahuan Ibu Balita Sesudah Diberi Penyuluhan Tentang Tumbuh Kembang Balita Di Posyandu Dukuh Nogo Desa Karang Waluh Kecamatan Sampung Kabupaten Ponorogo

\begin{tabular}{cccc}
\hline No. & Pengetahuan & $\mathrm{N}$ & $\%$ \\
\hline 1 & Baik & 24 & 55,8 \\
\hline 2 & Cukup & 18 & 41,9 \\
\hline 3 & Kurang & 1 & 2,3 \\
\hline & Total & 43 & 100 \\
\hline
\end{tabular}

Berdasarkan tabel diatas menunjukkan bahwa pengetahuna setelah diberikan penyuluhan sebagian besar $24(55,8 \%)$ berpengetahuan baik..

Tabel 3 Tabulasi Silang Perbedaan Pengetahuan Ibu Balita Sebelum Dan Sesudah Diberi Penyuluhan Tentang Tumbuh Kembang Balita Di Posyandu Dukuh Nogo Desa Karang Waluh Kecamatan Sampung Kabupaten Ponorogo

\begin{tabular}{|c|c|c|c|c|c|c|c|c|}
\hline \multirow{3}{*}{$\begin{array}{l}\text { Pengetahuan } \\
\text { Sebelum }\end{array}$} & \multicolumn{6}{|c|}{ Pengetahuan Sesudah } & \multicolumn{2}{|c|}{ Total } \\
\hline & \multicolumn{2}{|c|}{ Baik } & \multicolumn{2}{|c|}{ Cukup } & \multicolumn{2}{|c|}{ Kurang } & & \\
\hline & $\mathrm{N}$ & $\%$ & $\mathrm{~N}$ & $\%$ & $\mathrm{~N}$ & $\%$ & $\mathrm{~N}$ & $\%$ \\
\hline Baik & 5 & 100 & 0 & 0 & 0 & 0 & 5 & 11,7 \\
\hline Cukup & 10 & 83,3 & 2 & 16,7 & 0 & 0 & 12 & 27,9 \\
\hline Kurang & 9 & 34,6 & 16 & 61,5 & 1 & 1 & 26 & 60,4 \\
\hline \multirow[t]{2}{*}{ Total } & 24 & 55,8 & 18 & 41,9 & 1 & 1 & 43 & 100 \\
\hline & \multicolumn{3}{|c|}{ P Value : 0,000} & & \multicolumn{2}{|c|}{$\alpha: 0,05$} & & \\
\hline
\end{tabular}

Berdasarkan tabel diatas menunjukkan hampir seluruhnya $10(83,3 \%)$ berpengetahuan cukup setelah diberi penyuluhan berpengetahuan baik. Dari hasil uji analisis menggunakan $\mathrm{T}-$ Test didapatkan P Value 0,000 dengan $\alpha$ : 0,05 yang artinya Perbedaan Pengetahuan Ibu Balita 
Sebelum Dan Sesudah Diberi Penyuluhan Tentang Tumbuh Kembang Balita Di Posyandu Dukuh Nogo Desa Karang Waluh Kecamatan Sampung Kabupaten Ponorogo. Hal ini diperkuat dengan penelitian yang dilakukan oleh Hariyanto dan Delya (2017) yang menyatakan bahwa ada perbedaan pengetahuan sebelum dan sesudah tentang status gizi.

Adanya perbedaan pengetahuan tentang tumbuh kembang disebabkan oleh factor seperti umur dan pendidikan. Sehingga semakin cukup umur seorang ibu maka tingkat kematangan dalam berfikir dan bekerja menjadi lebih matang. Didalam masyarakat pun semakin dewasa seseorang maka akan semakin dipercayai. Begitu juga degan factor pendidikan, semakin tinggi pendidikan seseorang maka semakin mudah menerima informasi sehingga semakin banyak pengetahuan yang dimilikinya. Selain itu factor eksternal juga berpengaruh seperti lingkungan, lingkungan berpengaruh terhadap perkembangan dan perilaku orang tua atau kelompok. Sosial budaya, system sosial budaya dapat mempengaruhi sikan dan menerima informasi. (Hariyanto, 2017).

Pendidikan kesehatan termasuk penyuluhan merupakan suatu penyampaian informasi yang berhubungan dengan kesehatan sehingga dapat mempengaruhi pengetahuan dan diharapkan dapat memberikan motovasi kepada masyarakat terhadap tumbuh kembang anak, penyuluhan berdampak positif dalam perubahan perilaku akibat proses belajar sebab belajar adalah proses perubahan dari tidak tahu menjadi tahu. (Raehan,.)

\section{KESIMPULAN}

Ada Perbedaan Pengetahuan Ibu Balita Sebelum Dan Sesudah Diberi Penyuluhan Tentang Tumbuh Kembang Balita Di Posyandu Dukuh Nogo Desa Karang Waluh Kecamatan Sampung Kabupaten Ponorogo, diharapkan media penyuluhan bisa menjadi salah satu media untuk meningkatkan pengetahuan Ibu tentang tumbuh kembang anak.

\section{UCAPAN TERIMA KASIH}

Ucapan terima kasih kami ucapkan kepada responden yang bersedia menjadi sampel penelitian, Kader Posyandu Dukuh yang sangat membantu pengumpulan data penelitian, serta pihak-pihak lain yang membantu dalam penyusunan penelitian ini

\section{DAFTAR PUSTAKA}

A Kurniawati, L Hanifah, 2015, Hubungan Pengetahuan Ibu entang Stimulasi Tumbuh Kembang Balita dengan Perkembangan Balita usia 12 - 36 bulan di Posyandu 
Kasih Ibu Banyu Urip klego Boyolali, Jurnal Kebidanan Indonesia: Juornal of Indonesia Midwifery 6 (1) 2015

Adriana, 2013, Tumbuh Kembang dan Terapi Anak, Jakarta: Salemba Medika

Arikunto. 2010. Prosedur Penelitian Suatu Pendekatan. Edisi revisi. Jakarta : Rineka Cipta.

Azrimaidaliza Azrimaidaliza, Annisa Annisa, Anisa YKNP, 2019, Optimalisasi Tumbuh Kembang Balita melalui Promosi Gizi Seimbang di Kecamatan Koto Tengah Padang, Jurnal Ilmiah Pengabdian kepada Masyarakat 3 (2) Jul-Des 2019

Hariyanto, 2017, Perbedaan Pengetahuan Ibu dan Balita Sebelum dan Sesudah Dilakukan Penyuluhan Tentang Status Gizi Balita Umur 1 - 5 Tahun Di Posyandu 1 Cokromenggalan Kecamatan Ponorogo Kabupaten Ponorogo, Jurnal Delima Harapan, Vol 8 No 7 (Feb-Juli 2017)

Notoatmodjo. 2010. Metodologi Penelitian Kesehatan. Jakarta : Rineka Cipta.

Nursalam. 2001. Konsep Dan Penerapan Metodologi Penelitian Ilmu Keperawatan. Jakarta : Salemba Medika.

Raehan, 2020, Pengaruh Penyuluhan Kesehatan Terhadap Pengetahuan Ibu Tentang Tumbuh Kembang Anak Usia 3 - 5 tahun di Paud Buah Delima Di Lingkungan Galung Tengah Kabupaten Majene, Jurnal Media Bidan , Vol 4 No 2

Rohmah Eliya dan Sureni Ike, 2012, Pengaruh tingkat pendidikan dan pendapatan masyarakat terhadap gizi buruk di wilayah Kecamatan Sampung dan Kec. Jenangan Kab. Ponorogo, Jurnal Delima Harapan (ber ISSN) Volume 4/Hal 86-90

Soetjiningsih \& Ranuh U.N, 2014, Tumbuh Kembang Anak Edisi 2, Jakarta: EGC

Sudirman Sudirman, Hartati Hartati, Ayu Wulansari, 2017, Hubungan Pengetahuan Ibu dengan tahap Pencapaian Tumbuh Kembang Balita usia Sudirman Sudirman, Hartati Hartati, Ayu Wulansari, 2017, Hubungan Pengetahuan Ibu dengan tahap Pencapaian Tumbuh Kembang Balita usia 4-5 tahun di Kelurahan Medono Kota Pekalongan, Jurnal Litbang Kota Pekalongan 12, 2017 